\title{
Thoughts on the Precarious State of Medicinal Herbs and Plants in the Tibet Autonomous Region and Ideas About Their Protection
}

\author{
Kalden Nyima \\ Translated by Tsering D. Gonkatsang
}

\begin{abstract}
This paper, translated from the Tibetan original, presents the author's viewpoint on the current situation regarding the protection of medicinal herbs and vegetation-the sources of Tibetan medicine - and makes recommendations on measures that should be taken for their protection in the future. The article also includes an appendix listing species names of plants that are A) particularly rare or endangered, and B) the subjects of conservation efforts and/or cultivation trials through the Project to Strengthen Traditional Tibetan Medicine (PSTTM), which is based in Lhasa, Tibet Autonomous Region (TAR), China.
\end{abstract}

Keywords

Tibetan medicine, protection, natural environment

\section{Editors' Introduction}

The work of Kalden Nyima presents readers with invaluable insight into the ways some contemporary Tibetan medical practitioners understand the problems of biodiversity depletion, as well as how they frame and address issues related to conservation and sustainable use of materia medica. Kalden Nyima's article, which has been translated from the Tibetan original by Tsering D. Gonkatsang and further elaborated through the editorial process, presents an opportunity to engage with Tibetan ways of knowing plants and understanding the causes and conditions giving rise to resource scarcity.

In what follows, Kalden Nyima categorizes thirty-eight different species according to various levels of danger or risk posed to them by overharvesting, commercial production, environmental degradation, etc. It is interesting to note the ways that Kalden Nyima's classificatory scheme relates to-and yet departs from-global conservation and development classification systems that attempt to rank and capture orders of endangerment. Consider the 
International Union for the Conservation of Nature's (IUCN) Red-list ranking of species from extinct or extinct in the wild to those that are critically endangered, endangered, vulnerable, conservation dependent, or near threatened (http://www.iucnredlist.org/). Such global biodiversity conservation organizations and the views Kalden Nyima expresses share the sensibility that aspects of modern life and an economy of resource extraction are viewed as direct contributors to the decline of plant species. Yet Kalden Nyima's framing of these issues refers directly to the morally problematic nature of these activities, as well as their implications for the potency of medicines-areas of concern that are often secondary to, or absent from, political ecology perspectives on these issues. In Kalden Nyima's account, patterns of deleterious resource use are further linked to behaviour of human beings who interact with and depend on medicinal plants and the greater Plateau environment, but who might not be knowledgeable about proper harvesting techniques.

The paper further enumerates specific guidelines for cultivation trials. While qualitative in nature, they are also practical and instructive. Like other papers given during the panel at ICTAM VII, Kalden Nyima's work includes both specific and general commentary on the urgent need to protect medicinal plant resources on the Tibetan Plateau-from species lists and descriptions of how roots and seeds should be propagated to general social, ecological, and ethical appeals for 'right practice' when it comes to the use of these resources.

It is worth noting a few points about the language Kalden Nyima has chosen to use, and the general relationship between concepts such as 'protection' and 'preservation' in Tibetan and how these often and imperfectly translate into other quite specific terms such as 'conservation' and 'sustainability'. The spirit of careful and considered action rests at the core of Tibetan terms such as srung skyob and English terms such as conservation, and yet the two concepts have distinct meanings at the level of epistemology and social practice. In this translation of Kalden Nyima's work, we have explicitly chosen not to gloss concepts such as srung skyob as 'conservation' but to translate this and related terms as processes of protection, safeguarding, and defence.

Finally, we make a note of the ways Kalden Nyima chooses to begin and end his essay-essentially with invocations in verse. Much more than an epigraph, acknowledgments or a conclusion in the traditional academic sense, this framing is at once rhetorically standard practice in many genres of Tibetan literature and a concrete reminder to the reader of the lineage from which the author emerges. These opening and closing lines express a combination of humility and expertise, by turns. Kalden Nyima is a Tibetan medical doctor who graduated from the Tibetan Medical College of the Tibet Autonomous 
Region (TAR). He is currently working with PSTTM and is engaged in developing the Tibetan medical tradition whilst also being involved in the campaign to protect Tibetan medicinal resources. He is concurrently pursuing doctoral studies at the Tibetan Medical College.

\section{Introduction}

In the pristine Land of Medicinal Herbs, the Roof of the World, Concocting pure and unadulterated medicine from natural sources, And rooting out the afflictions of body and mind of sentient beings, The learned Master Healer, Lord Yuthok [Yontan Gonpo], ${ }^{1}$ graced.

In the Land of Snows, encyclopaedic medicinal knowledge, precious like jewels, [Which has been] preserved, propagated and promoted by learned masters like De'u Mar, ${ }^{2}$

And other great master healers, past ancestors as well as the living,

To all of them, the root Gurus, I offer my obeisance.

The inanimate universe as vessel and all the animate beings that inhabit it,

Are essentially the integration of the five elements (byung ba lnga) in an interdependent relationship.

For the sake of longevity and wellbeing of all living beings,

Protecting this natural environment [of ours] is a worthwhile endeavour.

Having offered the above introductory remarks, I state that the subject of discussion [in this paper] will be the prevailing situation regarding the safeguarding of resources for Tibetan medicine in the context of environmental protection in general. I will also suggest views on the possible protective measures we may adopt in the future.

\footnotetext{
${ }^{1}$ Yuthog Yontan Gonpo ( $g \cdot y u$ thog yon btan mgon po) refers to a mytho-historical figure or figures. The 'elder' Yuthog is said to have lived in the seventh century, during the reign of King Songtsen Gampo, and to have been instrumental in the codification of the Fourfold Treatise (rgyud bzhi), texts which are fundamental to the Tibetan medical corpus. According to historical sources and recent scholarship (cf. Yang Ga 2010), it is likely that the figure known as Yuthog Yontan Gompo the 'younger' was an actual person who lived during the twelfth century, and who played a key role in the development of Tibetan medicine, including the compilation and editing of the Fourfold Treatise into much the same form and content in which it exists today. Regardless of the historical validity regarding his elder and younger incarnations, this figure remains central to Tibetan medical identity.

${ }^{2}$ De'u Mar (dil dmar dge bshes bstan 'dzin phun tshogs) was a famous eighteenth-century Tibetan scholar and physician who was the author of the commentary Crystal Mirror, Crystal Rosary (dri med shel gong dri med shel phreng).
} 


\section{Current state of the natural environment in the Tibet Autonomous Region}

These days, the reckless excavation and exploitation of mineral resources, and the serious pollution of the environment with non-recyclable garbage and impurities, ${ }^{3}$ has caused the deterioration of the natural environment including the rapid melting of snow-mountains and glaciers, diminishing water in rivers and lakes, the desertification of grasslands, and so on. Because of this, natural calamities such as earthquakes, snow storms, drought etc. have negatively impacted the survival chances of wild animals, causing a rapid decline in their population. Likewise, we have seen a decline in the growth of natural vegetation and medicinal herbs such that either they no longer grow where they used to, or they grow poorly and in reduced quantities and quality, including medicinal potency (nus $p a$ ). Furthermore, given that the 'summer grass winter insect' (dbyar rtswa dgun 'bu, Ophiocordyceps sinensis, see paper by Winkler, this volume) is found in most regions of Tibet, children going to pick it are missing out on education; young people and adults lack any vocational skills. Those who care about environmental damage and recognize the importance of herbal medicine and are willing to protect it are declining in number.

\section{Future prospects of natural medicinal resources exclusive to the Tibetan Plateau}

Visits to many of the larger institutions producing Tibetan medicinal pills reveal that the number of people picking medicinal herbs and plants that are native to Tibet has increased hundred-fold but [that this enterprise is] driven by greed rather than a proper understanding of how to harvest medicinal plants. Medicinal resources are exploited recklessly, resulting in depletion year after year, and even extinction in the case of a few plants. For example, the plants such as gang ga' chung [Gentiana urnula] whose leaves, stalk, flower and fruits can be used for medicine, are decreasing in number and distribution by the year because the plant is being completely uprooted during harvesting. In addition, sro lo dmar po [Rhodiola crenulata], whose roots can be used in medicine, is also being uprooted completely irrespective of the

3 The author uses the term gad snyigs dkar po to refer to 'garbage and impurities'. The meaning of the term 'white' in this phrase is taken to mean 'non-recyclable' waste, as this is how the term was interpreted during the IASTAM conference in Bhutan, as referenced in the transcripts from the panel from which the essays in this special issue have been developed. 
plant's maturity so that no new plants grow in these habitats the next year. These days, some of the herbs that grow in Tibet have become more expensive than khrog sman (raw unprepared substance of medicine) obtained in India and China. For example, one rgya $m a^{4}$ of a ru ra [Terminalia chebula] sells for RMB 6 (US\$0.90) and one rgya ma of gang ga' chung sells for RMB 50 (US\$7.50).

In instances in which the [requisite] medicinal herbs and plant ingredients are unavailable, then the Tibetan medicinal compound will be incomplete. Not only will the medicine lose its curative potency but also the unique properties of traditional Tibetan medicine will decline as well. Therefore, it would be unforgivable to ignore the importance of medicinal herbs and plants and to leave these situations [of resource depletion and rising costs] as they are at present.

I will now present a classification of three different degrees of danger for a variety of key medicinal plant species. The first category represents plants that are in the most critical state of disappearing; this category includes twelve species. The second category represents plants that are not as urgently in danger as the first, but are still threatened; this category also includes twelve species. The third category represents plants that are at risk, of which I list sixteen species. The basis on which I have classified them into three categories are as follows: 1 . They are geographically limited to a few areas; 2 . The quality of product is inferior; 3. The plant has a multiplicity of usages; 4 . There exists sub-standard practices with respect to usage; and 5. The plants are difficult to cultivate. The names of the plants in each category are listed in the appendix.

\section{Current protective measures in practice}

These days, in various parts of the TAR, centres for the plantation of medicinal herbs and plants have gotten underway on an experimental basis. These centres and projects are cultivating species that are relatively easier to propagate; other categories are under trial. We at PSTTM, too, have cooperated with the relevant departments in according a high priority to the issue of protecting the natural resources of [Tibetan] medicine. We have participated in seminars on Tibetan medicine and organized several workshops on the ways to protect medicinal resources and to standardize harvesting practices. We have also established cultivation trials for some 20 species, which are being grown on an experimental basis. In order to avoid the high incidence of waste

${ }^{4} 1 \mathrm{rgya} m a=0.5 \mathrm{~kg}$. 
[of natural resources] through unnecessary exploitation [which is often the result of improper harvesting techniques], we have worked with local people to inform and educate them repeatedly about the importance of protecting medicinal resources and the proper ways to appropriate and use these plants, by way of distributing illustrated manuals on the subject.

\section{Fundamental approaches to cultivating medicinal herbs and plants for Tibetan medicine}

Broadly speaking, in the approach to cultivating medicinal resources, planting seeds from fruits and (trans)planting roots are the two main methods. Depending on the differences in the way medicinal plants grow and their unique properties, some require their seeds to be planted while they are fresh and recently harvested from fruits, whereas others require parts of their roots to be transplanted, also while freshly harvested. Some species can have both flowering seeds and parts of the roots transplanted while others can only have either their roots or flowering seeds planted. Still other species cannot be planted either from flowering seeds or root cuttings. These two main methods of cultivation can be summarized as follows:

\section{Cultivation from flowering seeds}

First, [for this method of cultivation] the medicinal source should be the ripened seed of the flower that is not older than two years. Second, the sowing field should be loamy, fine-grained and free from stones and pebbles. Third, if soaked in water before planting, the hard fruit (seeds) of some material medica may grow more quickly and in greater quantity. Fourth, until the shoots appear above ground, strict care should be taken with respect to temperature and moisture control. Fifth, these types of plants share the property of being easy to plant, spreading fast and growing in large quantities. Sixth and finally, such plants have the convenience of being able to be bought and sold, as well as being able to be transported long distances.

\section{Transplanting roots}

First, the root should be in good condition with nodules and 'eyes' that can be separated into parts. Second, towards the end of autumn, the main ball of the roots can be used for medicine whereas bits with nodules that are neither rotten nor dry and without leaves or cuts, should be buried deep in the earth 
and transplanted the next spring. Third, the root bit should neither be shrivelled nor dried but fresh. Fourth, digging the earth deep and the method of transplanting should be done properly. Fifth and finally, attention should be paid to ensure the right size and appropriate timing for transplanting.

In summary, it is extremely important to pay attention to factors such as the altitude at which the plant grows, the sunny or shady side of the area in which it thrives, and so on, when considering cultivation.

\section{Measures to protect the environment and medicinal resources with an appeal to action}

We should, in the future, by upholding the values and attitudes of our forebears as the foundation, learn, adopt, and implement modern environmental protection measures such as those I innumerate below. First, strict laws should be passed on the protection of the environment and medicinal resources. In the event of violation of such laws, the higher authorities should be moved to take action. Second, awareness should be raised about the damaging consequences of non-recyclable garbage and impurities on the environment, damage limitation measures should be taken against such practices, and people should be educated about this. Third, in the areas where the 'summer grass winter insect' grows in abundance, there is a danger of people getting lured into the temporary benefits of cash income with high prices, and there is a consequent risk of the [environmental] situation changing for the worse. Therefore, efforts should be made to educate people about the importance and benefits of protecting medicinal resources. The planned exploitation [of such resources] for sustained/sustainable income and related benefits should be explained, through examples. Fourth, repeated efforts must be made to educate, inform, and raise awareness among local people about the need to protect medicinal resources and the [scientific] methods of exploiting such resources. Efforts to publish and disseminate books and literature on the subject should be strengthened, to help ensure that such [scarce] medicinal resources are not wasted unnecessarily. Fifth, by establishing close and [direct] contact between the local people who collect the medicinal resources and the companies who process these materials to make medicines, optimum profits/ benefits for the locals should be ensured. Sixth, experiments in the cultivation of medicinal resources should be continued. In particular, to prevent loss of potency of the medicinal plants with respect to the unique 'cool' and 'warm' property theory of Tibetan medicine, such experimental cultivation plots should be located in specific places: one each on the sunny and shady sides of 
high altitude environments and then [for comparison] one each in the sunny and shady sides of a low altitude place. Seventh, since some categories of medicinal resources may not grow well and thereby run the risk of losing their normal potency, they should be grown and conserved in situ, with the area fenced and guarded for protection. Eighth, these days in the TAR, for example, since Tibetan medical products are regarded as a mainstay of the Tibetan economy, and since medicinal resources are the critical factor for the success of the industry, authorities are requested to bring to bear the full force of the government's power to protect them. Finally, if a close network of relationships can be established between the organizations responsible for protecting medicinal resources and those responsible for producing medicine, [if] a common goal [can be] developed, and [if all are] united in their efforts, even better results can be achieved.

\section{Conclusion}

Given an undeveloped and unperfected intellect,

For all errors of misinterpretations due to misunderstandings,

I atone humbly before the gracious presence of all qualified masters

And beseech that my cataract of ignorance be removed.

By virtue of the merit accruing from this little effort of mine,

May the shower of medicinal elixir of the Land of Snows,

For the sentient beings assailed by a host of tormenting illnesses,

Continue as an inexhaustible and beneficial stream of nourishment.

\section{References $^{5}$}

Dga' ba Rdo rje 1998, 'khrungs dpe dri med shel gyi me long. (Stainless Crystal Mirror on the Classification of Medicinal Plants and their Identification: A Compendium of Tibetan materia medica.) Lhasa: Nationalities Publishing House.

G.yu thog Yon tan Mgon po (no date), bdud rtsi snying po yan lag brgyad pa gsang ba man ngag gi rgyud. (Essence of the Elixir: the Eight-Limbed Secret Oral Instruction Tantra). Lhasa: Tibet Nationalities Publishing House.

Skal bzang Don grub 2006, mtsho bod mtho sgang gi skye dngos sman rdzas dang skye khamskhr yug gi 'brel ba'i skor la cung zad dpyad pa (Limited Research on the Relationship between the Medicinal Resources and the Ecology of the Qinghai-Tibet Plateau). Proceedings of the Seminar Propagating Tibetan Medical Culture.

5 Editors' note: at the time of publication, we were not able to obtain full citations for several of the references cited here. 
mdo dbus mtho sgang gi skye khams khor yug srung skyobs byed pa'i skor brjod pa lhag bsam padma dkar po'i chun po by dpal ris bsod nams tshe ring. (Sincere Comments on the Protection of the Ecology on the Central and Lower Tibetan Plateau, Bouquet of White Lotus). Lanzhou: Gansu Nationalities Publishing House.

Yang Ga 2010, On the Origins of the Rgyud Bzhi and the Relationship between Greek and Tibetan Medicines. PhD thesis, Department of Inner Asian and Altaic Studies, Harvard University. 